\title{
All-Solid-State Polymeric Membrane Ion-Selective Miniaturized Electrodes Based on a Nanoporous Gold Film as Solid Contact
}

\author{
Tanji Yin, ${ }^{\dagger \neq}$ Dawei Pan, ${ }^{\dagger}$ and Wei Qin ${ }^{* \dagger}$
}

${ }^{\dagger}$ Key Laboratory of Coastal Environmental Processes and Ecological Remediation and Shandong Provincial Key Laboratory of Coastal Environmental Processes, Yantai Institute of Coastal Zone Research, Chinese Academy of Sciences (YICCAS), Yantai, Shandong 264003, P. R. China

"University of the Chinese Academy of Sciences, Beijing 100049, P. R. China

\section{Supporting Information}

ABSTRACT: A new type of all-solid-state polymeric membrane ion-selective electrodes (ISEs) is developed by using a nanoporous gold (NPG) film as solid contact. The NPG film is in situ formed on the surface of a gold wire electrode by the multicyclic electrochemical alloying/dealloying method. The characteristics of the NPG film, such as the large surface area, high double layer capacitance, and good conductivity, have been demonstrated by cyclic voltammetry and electrochemical impedance spectroscopy. The NPG film offers a well-defined interface between the electronic conductor and the ion-selective membrane. The NPG filmbased all-solid-state $\mathrm{K}^{+}$ISE shows a stable Nernstian response within the concentration range from $10^{-6}$ to $10^{-2} \mathrm{M}$, and the detection limit is $4.0 \times 10^{-7} \mathrm{M}$. The proposed electrode exhibits an improved potential stability with a reduced water layer in comparison with the coated-wire $\mathrm{K}^{+}$-ISE, which is due to the bicontinuous electron- and ion-conducting properties of the ionophore-doped polymeric membrane/NPG film interlayer. Unlike the additionally coated intermediate layers as single-use solid contacts, the in situ formed NPG film as solid contact is reusable. This work provides a versatile method for fabricating the robust, reliable, and low-maintenance miniaturized ISEs.
$\mathrm{M}$ iniaturized ion-selective electrodes (ISEs) represent a promising field of research and applications in clinical monitoring and environmental analysis for their compact size, low cost, and high sensitivity in small sample volume. ${ }^{1}$ All-solidstate polymeric membrane ISEs offer an effective way for electrode miniaturization, due to their elimination of inner filling solution, convenient storage and maintenance, and ease of electrode orientation handling, ${ }^{2}$ as compared to traditional liquid-contact ISEs.

The coated-wire ISEs, as the original form of all-solid-state ISEs, are fabricated with the ion-selective membranes directly casted on the electronic conductors. ${ }^{3}$ Such sensor configuration shows potential instability and ill-reproducibility for long-term use, due to the lack of a thermodynamically well-defined interface between the electronic conductor and the ion-selective membrane. ${ }^{4}$ Additionally, an undesired water layer with about $100 \AA$ thickness under the ion-selective membrane is another resource of potential drift, ${ }^{5}$ which unintentionally acts as an inner filling solution with extremely small volume that reequilibrates on each and every change in sample composition and subsequently influences the boundary potential. ${ }^{6}$

Both sources of potential instability can be eliminated by applying a variety of materials as solid contacts, such as lipophilic redox-active self-assembled monolayers, ${ }^{7}$ conducting polymers, ${ }^{8}$ fullerene, ${ }^{9}$ three-dimensionally ordered macroporous (3DOM) carbon, ${ }^{10}$ carbon nanotubes, ${ }^{11}$ graphene, ${ }^{12,13}$ gold nanoparticles, ${ }^{14}$ and nanoclusters. ${ }^{15}$ However, some of those materials may be not suitable for developing robust miniaturized ISEs. For example, the fabrication of 3DOM carbon is complicated and the size of 3DOM carbon is not easy to miniaturize, although $3 \mathrm{DOM}$ carbon-based solid-contact $\mathrm{K}^{+}$ISEs exhibits excellent long-term potential stability. ${ }^{10}$ Multilayer drop-casting methods are commonly used to prepare carbonbased nanomaterials as solid contacts. ${ }^{11,12}$ However, not only the process is tedious, but also the poor solubility of carbon materials and the weak adhesion on the electronic conductors would influence the development of miniaturized ISEs. More recently, the colloid-imprinted mesoporous carbon with poly(vinyl chloride) as binder was used to develop solidcontact ISEs. ${ }^{16}$ Porous glassy carbon loaded with ionophore and plasticizer has been designed to develop a solid-contact $\mathrm{Pb}^{2+}$-ISE with a detection limit at picomolar levels, ${ }^{17}$ while the size of porous glassy carbon cannot be freely handled, due to its hardness and brittleness. Additionally, conducting polymers,

Received: August 5, 2014

Accepted: October 16, 2014

Published: October 16, 2014 

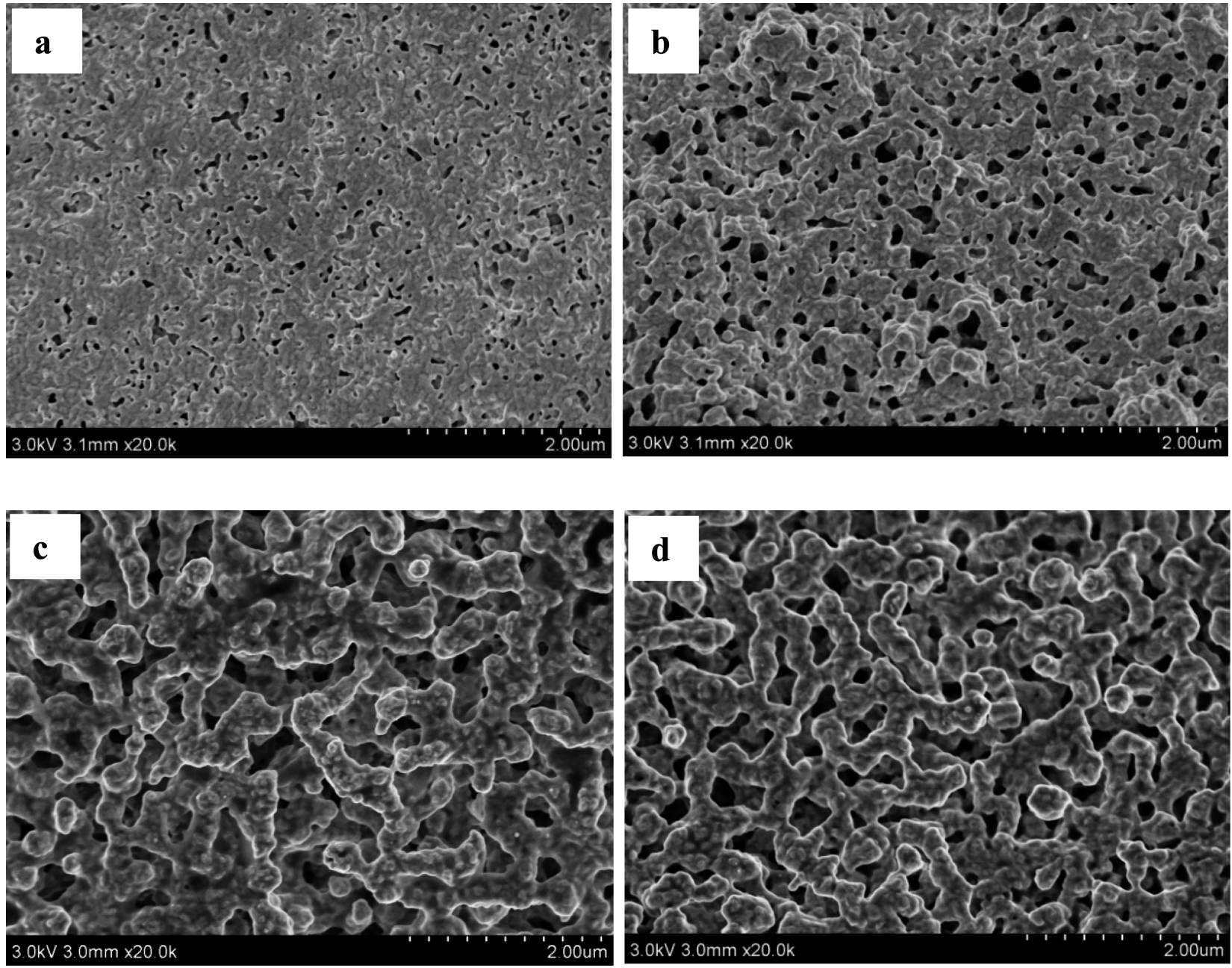

Figure 1. Field-emission scanning electron microscopy images of the nanoporous gold films prepared under different electrochemical alloying/ dealloying conditions: (a) the electrolyte, $0.8 \mathrm{M} \mathrm{ZnCl}_{2}$; scan rate, $10 \mathrm{mV} / \mathrm{s}$; cyclic number, 10 cycles; (b) the electrolyte, $1.6 \mathrm{M} \mathrm{ZnCl}_{2}$; scan rate, 50 $\mathrm{mV} / \mathrm{s}$; cyclic number, 10 cycles; (c) the electrolyte, $1.6 \mathrm{M} \mathrm{ZnCl}_{2}$; scan rate, $10 \mathrm{mV} / \mathrm{s}$; cyclic number, 10 cycles; (d) the electrolyte, $1.6 \mathrm{M} \mathrm{ZnCl}_{2}$; scan rate, $10 \mathrm{mV} / \mathrm{s}$; cyclic number, 15 cycles.

such as polypyrrole, polyaniline, and poly(3, 4-ethlyenedioxythiophene), could be conveniently electrodeposited on the electronic conductors as solid-contact materials of ISEs. However, they may suffer from some limitations, such as light sensitivity, ${ }^{18}$ remnants of salt from the polymerization process, ${ }^{19}$ and the undesired electrochemical side reactions with redox interferences, dissolved oxygen, and $\mathrm{CO}_{2}{ }^{8}$ In recent years, the conducting polymer, poly(3-octylthiophene) (POT), has been widely used as an ion-to-electron transducer to develop solid-contact polymeric membrane ion-selective miniaturized electrodes, due to its highly lipophilicity and low spontaneous decomposition in comparison with other conducting polymers. ${ }^{20,21}$ However, the uptake of POT by the ionselective membrane limits the potentiometric performance of solid-contact ISEs. $^{22}$ Moreover, most of these additional intermediate layers as solid contacts between the electronic conductors and ion-selective membranes are not suitable for reuse, and fresh solid-contact transducers are always required when changing the ion-selective membranes.

Herein, we report a self-supported gold wire electrode with a nanoporous gold (NPG) film structure for developing all-solidstate ISEs. The seamless NPG film is in situ formed on the surface of the gold wire electrode, which avoids the additional materials as solid contacts and is easy to miniaturize and reuse. With the large surface area, good conductivity, and high double layer capacitance, the NPG film is favorable for developing stable and reliable all-solid-state miniaturized ISEs. By using $\mathrm{K}^{+}$ as the model, the potentiometric characteristics of the proposed NPG film-based all-solid-state $\mathrm{K}^{+}$-ISEs are shown.

\section{EXPERIMENTAL SECTION}

Reagents and Materials. Valinomycin, sodium tetrakis [3, 5-bis(trifluoromethyl) phenyl] borate (NaTFPB), 2-nitrophenyl octyl ether (o-NPOE), and high molecular weight poly(vinyl chloride) (PVC) were purchased from SigmaAldrich. Gold wire (99.999\%, $0.25 \mathrm{~mm}$ in diameter), zinc plate $(99.99 \%, 1.0 \mathrm{~mm}$ thick, $25 \times 25 \mathrm{~mm}$ ), and zinc wire (99.99\%, $0.5 \mathrm{~mm}$ in diameter) were purchased from Alfa Aesar. All other chemicals were of analytical reagent grade. Deionized water (18.2 $\mathrm{M} \Omega \mathrm{cm}$ specific resistance) obtained with a Pall Cascada laboratory water system was used throughout.

Electrode Preparation. A gold wire with $1 \mathrm{~cm}$ length and $250 \mu \mathrm{m}$ diameter was soldered to a copper wire and then sealed in a glass tube so that the length of the protruded gold distal end was about $3 \mathrm{~mm}$. After being cleaned by acetone, alcohol, and deionized water, the homemade gold electrodes were used 
to prepare the NPG films. The multicyclic electrochemical alloying/dealloying method was applied in a benzyl alcohol (BA) solution containing $\mathrm{ZnCl}_{2}$ with a three-electrode system comprising the gold wire electrode as the working electrode, a $\mathrm{Zn}$ wire as the reference electrode, and a $\mathrm{Zn}$ plate as the auxiliary electrode. ${ }^{23}$ The electrochemical cycles were first recorded at $120{ }^{\circ} \mathrm{C}$ from the open circuit potential to $-0.72 \mathrm{~V}$ in order to predeposit $\mathrm{Zn}$ on the gold surface and then repeatedly scanned in the potential range from -0.72 to $1.88 \mathrm{~V}$ (vs $\mathrm{Zn}$ ). The obtained NPG film-based electrodes were finally rinsed by benzyl alcohol, ethanol, and deionized water in sequence.

The $\mathrm{K}^{+}$ion-selective membrane (ISM) for the all-solid-state ISEs contained $1.0 \mathrm{wt} \%$ valinomycin, $0.6 \mathrm{wt} \% \mathrm{NaTFPB}, 32.8$ wt \% PVC, and $65.6 \mathrm{wt} \% o$-NPOE. The membrane cocktail was prepared by dissolving $200 \mathrm{mg}$ of the membrane component in $1.5 \mathrm{~mL}$ of tetrahydrofuran (THF) and applied by coating the NPG film-based electrodes along their length for five times at a $10 \mathrm{~min}$ interval. The prepared all-solid-state $\mathrm{K}^{+}$ISEs were finally left to dry. For comparison, the coated-wire $\mathrm{K}^{+}$-ISEs were fabricated with the $\mathrm{K}^{+}$-ISM directly casted on the polished gold wire electrodes. The above prepared electrodes are denoted as $\mathrm{Au} / \mathrm{NPG} / \mathrm{K}^{+}$-ISM and $\mathrm{Au} / \mathrm{K}^{+}$-ISM electrodes, respectively.

Apparatus and Measurements. Electrochemical impedance spectroscopy (EIS) and cyclic voltammetry (CV) were carried out by using a CHI660C electrochemical workstation (Shanghai Chenhua Apparatus Corporation, China) in a onecompartment three-electrode cell where the electrode under study was used as the working electrode. The reference and auxiliary electrodes were $\mathrm{Ag} / \mathrm{AgCl}(3 \mathrm{M} \mathrm{KCl})$ and platinum wire, respectively. Potentiometric measurements were performed by the $\mathrm{CHI} 660 \mathrm{C}$ electrochemical workstation at $20 \pm 2$ ${ }^{\circ} \mathrm{C}$ with a double-junction $\mathrm{Ag} / \mathrm{AgCl}(3 \mathrm{M} \mathrm{KCl})$ reference electrode containing a $0.1 \mathrm{M} \mathrm{LiOAc}$ as salt bridge electrolyte in the galvanic cell: $\mathrm{Ag} / \mathrm{AgCl}(3 \mathrm{M} \mathrm{KCl}) / 0.1 \mathrm{M} \mathrm{LiOAc} /$ sample solution/ISM/NPG film/gold wire electrode. All potentiometric values were corrected for the liquid-junction potentials according to the Henderson equation, and the ion activities were calculated by the Debye-Hückel equation.

\section{RESULTS AND DISCUSSION}

Characterization of the Au/NPG Electrodes. The NPG film is in situ formed on the surface of the gold wire electrode by the multicyclic electrochemical alloying/dealloying method using a BA solution containing $\mathrm{ZnCl}_{2}{ }^{23}$ The mechanism is that the $\mathrm{Au}-\mathrm{Zn}$ alloy is formed via the electrodeposition of $\mathrm{Zn}^{2+}$ in the cathodic potential scan, while subsequently the dealloying of $\mathrm{Zn}$ is performed in the anodic potential scan, thus resulting in the NPG film with high surface area. ${ }^{23}$ The morphologies of the Au/NPG electrodes were characterized by using a fieldemission scanning electron microscope (FE-SEM, S-4800, Hitachi, Japan). As shown in Figure 1, the resulting porous structures of $\mathrm{Au} / \mathrm{NPG}$ electrodes are greatly influenced by the electrochemical alloying/dealloying conditions. Lower electrolyte concentrations of $\mathrm{ZnCl}_{2}(0.8 \mathrm{M})$ could cause less $\mathrm{Zn}$ deposited on the $\mathrm{Au}$ surface, while faster scan rates $(50 \mathrm{mV} / \mathrm{s})$ would induce inefficient redox $\mathrm{Au}-\mathrm{Zn}$ alloying/dealloying reactions. In both cases, the NPG films with low porosities are formed (Figure 1a,b). A well-defined three-dimensional bicontinuous nanoporous structure with quasi-periodic nanopore channels and Au ligaments (Figure 1c,d) can be obtained in $1.6 \mathrm{M} \mathrm{ZnCl}_{2}$ at a scan rate of $10 \mathrm{mV} / \mathrm{s}$ with more than 10 alloying/dealloying cycles.

$\mathrm{CV}$ was performed in $0.5 \mathrm{M} \mathrm{H}_{2} \mathrm{SO}_{4}$ to characterize the real surface areas of the $\mathrm{Au} / \mathrm{NPG}$ electrodes prepared under different electrochemical alloying/dealloying conditions. As shown in Figure 2, a symmetrical cathodic peak appears around

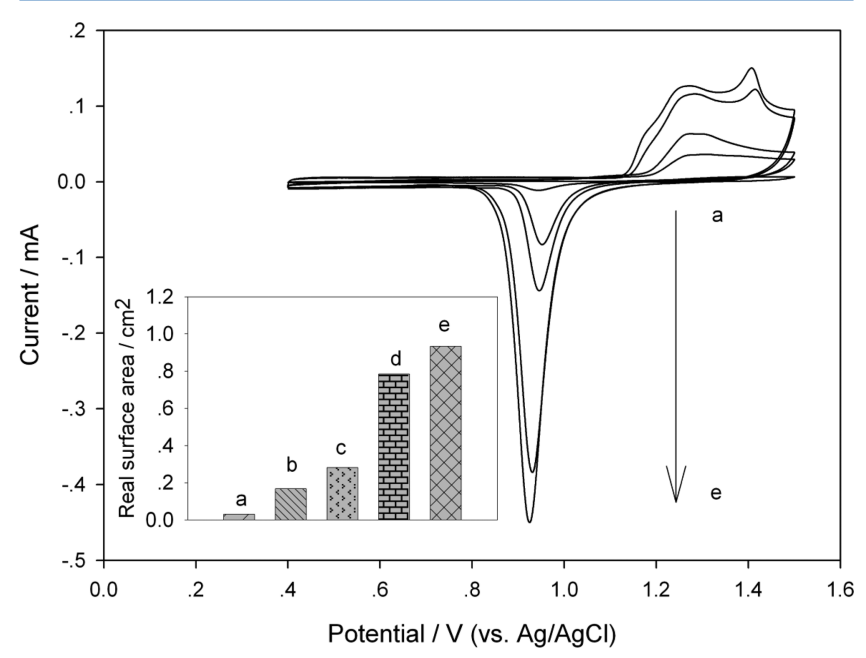

Figure 2. Cyclic voltammograms recorded in $0.5 \mathrm{M} \mathrm{H}_{2} \mathrm{SO}_{4}$ for the bare gold wire electrode (a) and the nanoporous gold film electrodes $(\mathrm{b}-\mathrm{e})$, prepared under the same electrochemical alloying/dealloying conditions as given in Figure 1a-d. Scan rate, $100 \mathrm{mV} / \mathrm{s}$. Inset: diagram showing the real surface areas of the bare gold wire electrode (a) and the nanoporous gold film electrodes $(b-e)$.

$0.93 \mathrm{~V}$, which is due to the electrochemical reduction of gold oxide. By integrating the charges from the reduction peaks, the real surface areas of $\mathrm{Au} / \mathrm{NPG}$ electrodes can be estimated (inset of Figure 2), according to an in situ method of oxygen adsorption from solution. ${ }^{24}$ It is shown that $\mathrm{Au} / \mathrm{NPG}$ electrodes exhibit much higher surface areas than that of the polished gold wire electrode. Additionally, the surface areas of the $\mathrm{Au} / \mathrm{NPG}$ electrodes are significantly influenced by the electrochemical alloying/dealloying conditions, which is in good agreement with the results obtained by FE-SEM.

It is known that a high surface area can cause an enhanced electrochemical double layer capacitance under given conditions, according to the equation $C=\varepsilon_{0} \varepsilon A / d$, where $\varepsilon_{0}$ and $\varepsilon$ are the permeability of free space and dielectric constant of the medium, $A$ is the plate area, and $d$ is the interplate distance. Therefore, $\mathrm{CV}$ in $0.1 \mathrm{M} \mathrm{KCl}$ was performed to investigate the differences among the electrical double layer capacitances for the bare gold wire electrode and Au/NPG electrodes. As shown in Figure 3, all of the cyclic voltammograms show similar shapes, exhibiting two region characteristics. One is related to the redox process from -0.5 to $0.1 \mathrm{~V}$, which is attributed to the oxygen reduction around $-0.1 \mathrm{~V}$. Indeed, the reduction peak decreases after bubbling $\mathrm{N}_{2}$ in the electrolyte solution for 15 min (Figure S1, Supporting Information). The other region is related to the capacitive process with a near-rectangular shape from 0.1 to $0.5 \mathrm{~V}$, which is not influenced by the presence or absence of oxygen (Figure S1, Supporting Information). Similar behaviors were also observed for single-walled carbon nanotubes (SWCNTs) and graphene as solid contacts in all-solidstate ISEs. ${ }^{25,26}$ As expected, the electrical double layer capacitances are found to be enhanced with the increase in the surface areas of the $\mathrm{Au} / \mathrm{NPG}$ electrodes. Moreover, the 


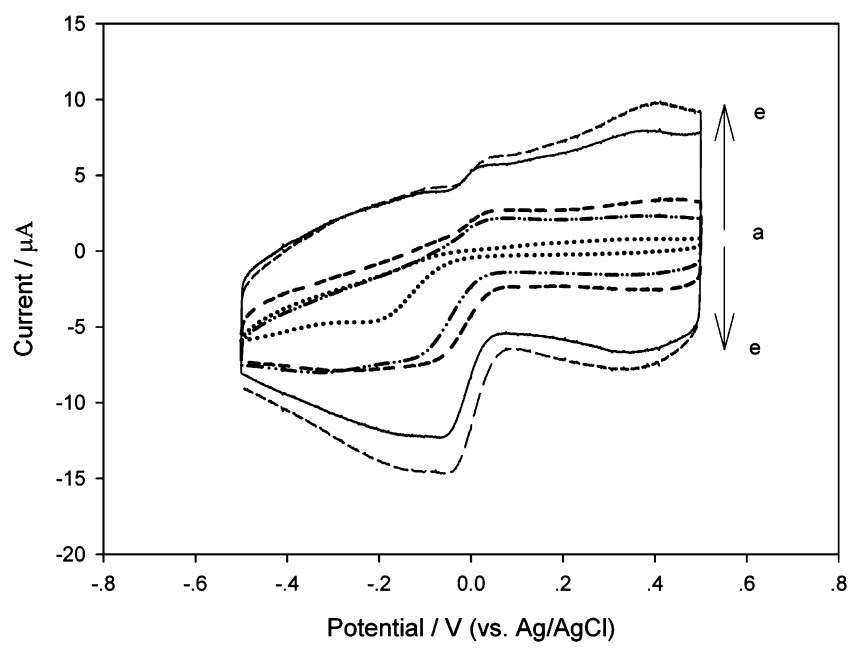

Figure 3. Cyclic voltammograms recorded in $0.1 \mathrm{M} \mathrm{KCl}$ for the bare gold wire electrode (a) and the nanoporous gold film electrodes (be), prepared under the same electrochemical alloying/dealloying conditions as given in Figure 1a-d. Scan rate, $100 \mathrm{mV} / \mathrm{s}$.

double layer capacitances of the NPG films prepared with more than 10 alloying/dealloying cycles are found to be not largely changed. Therefore, considering the preparation efficiency of the NPG film, the Au/NPG electrode with about $1 \mu \mathrm{m}$ thickness of the porous film, ${ }^{23}$ prepared in BA containing $1.6 \mathrm{M}$ $\mathrm{ZnCl}_{2}$ at a scan rate of $10 \mathrm{mV} / \mathrm{s}$ with 10 alloying/dealloying cycles, was further investigated.

EIS was performed in $0.1 \mathrm{M} \mathrm{KCl}$ to study the interfacial characteristics of the proposed Au/NPG electrode, including the internal resistance, charge transfer kinetics, and ion diffusion process. The impedance spectrum of the Au/NPG electrode shows a near $90^{\circ}$ capacitive line in the low-frequency region with the absence of a semicircle in the high-frequency region (Figure 4), which is similar to those of GC or Pt/ poly(3,4-ethylenedioxythiophene $)^{27,28}$ and GC/single-walled carbon nanotubes electrodes. ${ }^{25}$ This phenomenon indicates that there are fast interfacial ion- and electron-transfer

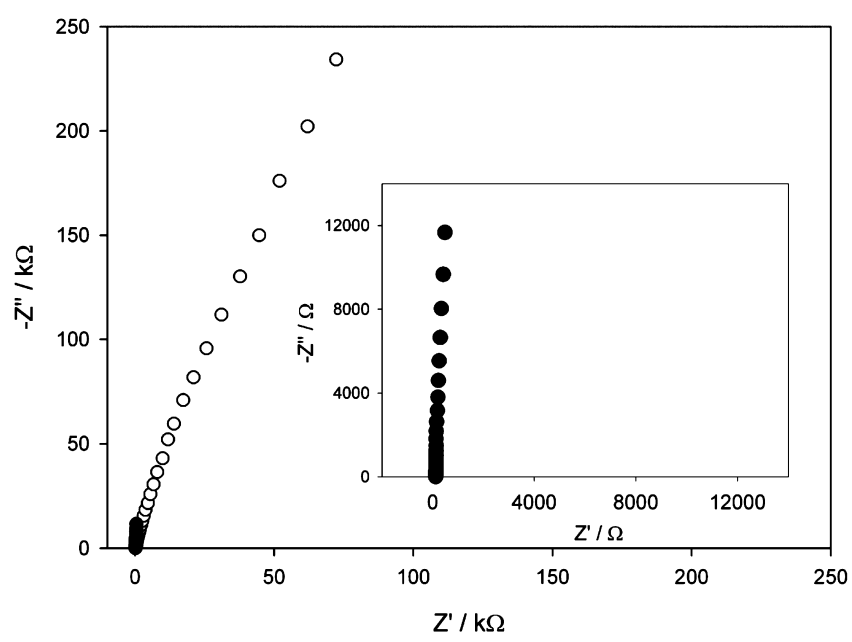

Figure 4. Impedance spectra for the bare gold wire electrode $(O)$ and nanoporous gold film electrode $(\bullet)$ in $0.1 \mathrm{M} \mathrm{KCl}$. Frequency range, $0.3 \mathrm{~Hz}$ to $10 \mathrm{kHz} ; E_{\mathrm{dc}} 0.2 \mathrm{~V} ; \Delta E_{\mathrm{dc}}, 10 \mathrm{mV}$. Inset: magnification of the impedance spectrum of the nanoporous gold film electrode, prepared under the same electrochemical alloying/dealloying conditions as given in Figure 1c. processes at the NPG film/solution interface in $0.1 \mathrm{M} \mathrm{KCl}$ and the Au/NPG electrode thus exhibits good conductivity. The high-frequency intersection with the $Z^{\prime}$ axis is highly dependent on the electrolyte concentration (Figure S2a, Supporting Information). The processes at the low-frequency region are seriously influenced by the dc potentials $\left(E_{\mathrm{dc}}=0.2\right.$, 0 , and $-0.2 \mathrm{~V}$ ) in the presence of oxygen (Figure S2b, Supporting Information). Surprisingly, at negative potential $\left(E_{\mathrm{dc}}=-0.2 \mathrm{~V}\right)$, the presence of a semicircle in the high frequency is not observed for the $\mathrm{Au} / \mathrm{NPG}$ electrode, which is different from the impedance spectra of SWCNTs and graphene as solid contacts. ${ }^{25,26}$ Additionally, the influence of oxygen on the impedance spectra of the Au/NPG electrode was studied (Figure S3, Supporting Information). No clear distinction on the impedance spectra of Au/NPG electrode was found in the presence and absence of oxygen, which indicates that the double layer capacitance of the Au/NPG electrode is not influenced by oxygen, according to the equation $C=-1 /\left(2 \pi f Z^{\prime \prime}\right)$, where $f$ is the frequency and $Z^{\prime \prime}$ is the imaginary part of the impedance. This result is in accordance with that of the capacitive region of cyclic voltammograms shown in Figure S1, Supporting Information.

Potentiometric Performance of the NPG Film-Based All-Solid-State ISEs. Due to its large surface area, good conductivity, and high double layer capacitance, the NPG film could offer a well-defined interface between the gold wire electrode and the ion-selective membrane. Therefore, the prepared $\mathrm{Au} / \mathrm{NPG}$ electrode was used to develop a robust and reliable all-solid-state polymeric membrane $\mathrm{K}^{+}$-ISE. After the electrode was conditioned in $10^{-3} \mathrm{M} \mathrm{KCl}$ overnight, the potentiometric response of the $\mathrm{Au} / \mathrm{NPG} / \mathrm{K}^{+}$-ISM electrode was measured by successively increasing $\mathrm{K}^{+}$activities. As illustrated in Figure 5, the proposed electrode shows a stable

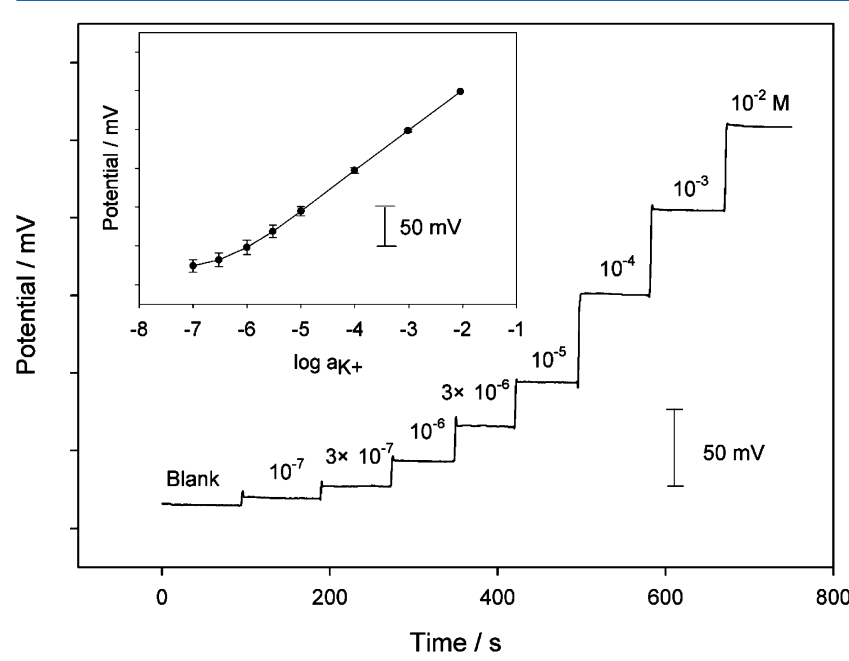

Figure 5. Time-dependent potential response trace of the Au/NPG/ $\mathrm{K}^{+}$-ISM electrode, conditioned in $10^{-3} \mathrm{M} \mathrm{KCl}$. Inset: calibration curve for the $\mathrm{Au} / \mathrm{NPG} / \mathrm{K}^{+}$-ISM electrode. Error bars represent the standard deviation for three identical electrodes.

potentiometric response without perturbations or random noises after each addition, and the response time is less than $10 \mathrm{~s}$, especially at low concentrations. The linear response range is from $10^{-6}$ to $10^{-2} \mathrm{M} \mathrm{KCl}$ with a slope of $54.2 \pm 0.7 \mathrm{mV} / \mathrm{dec}$ ( $\left.n=3, R^{2}=0.9998\right)$ (inset of Figure 5). The detection limit calculated as the interaction of the two slope lines is $4.0 \times 10^{-7}$ M. Additionally, the reproducibility of the proposed electrode 
was evaluated by alternatively measuring $10^{-5}$ and $10^{-4} \mathrm{M} \mathrm{KCl}$ (Figure S4, Supporting Information). The standard deviations of the potential values are $\pm 1.3 \mathrm{mV}$ for $10^{-5} \mathrm{M} \mathrm{KCl}$ and \pm 1.4 $\mathrm{mV}$ for $10^{-4} \mathrm{M} \mathrm{KCl}(n=4)$, respectively.

The potentiometric selectivity coefficients of the $\mathrm{Au} / \mathrm{K}^{+}$-ISM and $\mathrm{Au} / \mathrm{NPG} / \mathrm{K}^{+}$-ISM electrodes were investigated by using the separate solutions method. ${ }^{29}$ As shown in Table 1 , similar

Table 1. Potentiometric Selectivity Coefficients, $\log K_{\mathrm{K}+\mathrm{J}}$, of the $\mathrm{Au} / \mathrm{K}^{+}$-ISM and Au/NPG/ $/ \mathrm{K}^{+}$-ISM Electrodes, Obtained by the Separate Solution $\operatorname{Method}^{a}$

$\begin{array}{cccl}\begin{array}{c}\text { interfering } \\ \text { ions }\end{array} & \begin{array}{c}\mathrm{Au} / \mathrm{NPG} / \mathrm{K}^{+} \text {-ISM } \\ \text { electrode }\end{array} & \begin{array}{c}\text { Au/K } \\ \text { electrode }\end{array} & \begin{array}{c}\text { liquid-contact } \\ \text { counterpart }^{29}\end{array} \\ \mathrm{Na}^{+} & -4.67 \pm 0.03 & -4.05 \pm 0.41 & -4.50 \pm 0.10 \\ \mathrm{Mg}^{2+} & -7.84 \pm 0.10 & -7.89 \pm 0.08 & -7.50 \pm 0.10 \\ \mathrm{Ca}^{2+} & -6.70 \pm 0.08 & -7.01 \pm 0.08 & -6.90 \pm 0.10 \\ \mathrm{Li}^{+} & -4.58 \pm 0.14 & -4.98 \pm 0.20 & \text { N.D. } \\ \mathrm{NH}_{4}{ }^{+} & -2.00 \pm 0.16 & -1.55 \pm 0.20 & \text { N.D. }\end{array}$

${ }^{a}$ Mean value obtained from three corresponding pairs of concentrations of $\mathrm{K}^{+}$and the respective interfering ions in the measuring range of $10^{-1}$ to $10^{-2} \mathrm{M} \pm$ standard deviation $(n=3) .{ }^{b}$ Not determined.

selectivity coefficients are obtained for the $\mathrm{Au} / \mathrm{K}^{+}$-ISM and $\mathrm{Au} /$ $\mathrm{NPG} / \mathrm{K}^{+}$-ISM electrodes, which are also comparable to their liquid-contact counterpart. These results indicate that the selectivity of the proposed all-solid-state $\mathrm{K}^{+}$-ISE is not influenced by the NPG film attached on the backside of the $\mathrm{K}^{+}$-ISM. ${ }^{2}$

Potential Stability. Constant-current chronopotentiometry has been widely used as a convenient and fast experimental technique to evaluate the short-term potential stability of the all-solid-state ISEs. ${ }^{27}$ In this work, currents of $\pm 1 \mathrm{nA}$ were applied on the $\mathrm{Au} / \mathrm{K}^{+}$-ISM and $\mathrm{Au} / \mathrm{NPG} / \mathrm{K}^{+}$-ISM electrodes, and the potential responses were measured in $0.1 \mathrm{M} \mathrm{KCl}$ (Figure 6). According to the Ohm's law, $R=E / I$, where $E$ represents the change of potential and $I$ is the applied current; the total resistance $(R)$ of the $\mathrm{Au} / \mathrm{NPG} / \mathrm{K}^{+}$-ISM electrode is estimated to be about $1.2 \mathrm{M} \Omega$. The potential stability of the $\mathrm{Au} / \mathrm{NPG} / \mathrm{K}^{+}$-ISM electrode, derived from the ratio $\Delta E / \Delta t$, is $28.3 \pm 8.0 \mu \mathrm{V} / \mathrm{s}(n=3)$, which is much lower than that of the

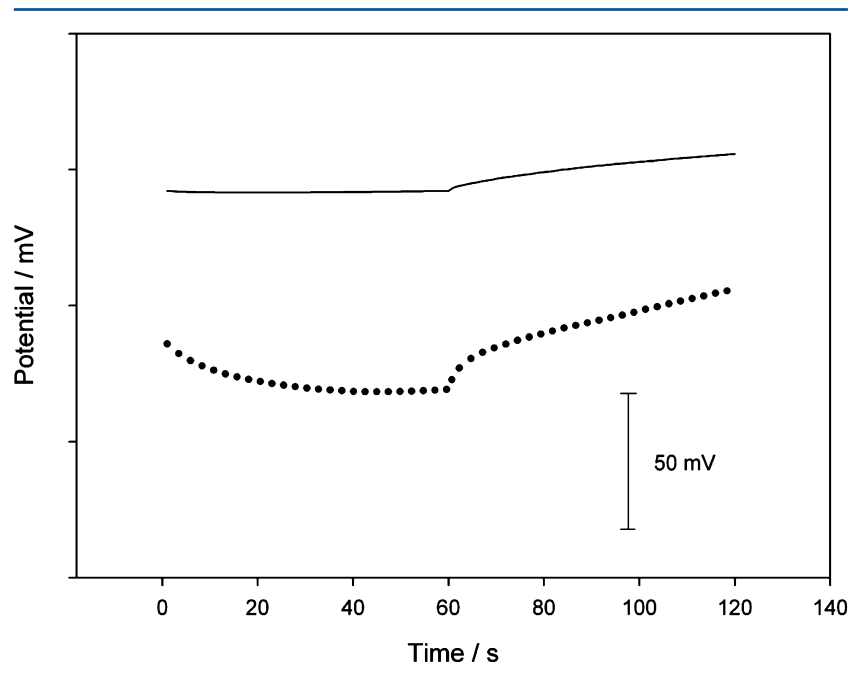

Figure 6. Chronopotentiograms for the $\mathrm{Au} / \mathrm{K}^{+}-\mathrm{ISM}$ (dotted line) and $\mathrm{Au} / \mathrm{NPG} / \mathrm{K}^{+}$-ISM electrodes (solid line) in $0.1 \mathrm{M} \mathrm{KCl}$. Applied current, $+1 \mathrm{nA}$ for $60 \mathrm{~s}$ and $-1 \mathrm{nA}$ for $60 \mathrm{~s}$.
$\mathrm{Au} / \mathrm{K}^{+}$-ISM electrode under the same conditions $(\Delta E / \Delta t=$ $293.3 \pm 13.0 \mu \mathrm{V} / \mathrm{s}, n=3)$. The high stability of the Au/NPG/ $\mathrm{K}^{+}$-ISM electrode may be attributed to the bicontinuous electron- and ion-conducting structure of the ionophore-doped polymeric membrane/NPG film interlayer. That is, the $\mathrm{Au}$ ligaments of the NPG film offer a continuous pathway for electron conduction, while ionic conductivity is provided by the quasi-periodic nanopore channels that are filled with the ionophore-doped polymeric membrane containing the cationic valinomycin complexes and the anionic exchanger. The mixed electron- and ion-conducting property of the ionophore-doped polymeric membrane/NPG film interlayer is similar to that of the 3DOM carbon-based solid contact. ${ }^{10}$

The medium-term stability of the Au/NPG/K $\mathrm{K}^{+}-\mathrm{ISM}$ electrode was evaluated under the zero current conditions by continuously monitoring the potential response in $10^{-3} \mathrm{M} \mathrm{KCl}$ solution for $20 \mathrm{~h}$ (Figure S5, Supporting Information). The obtained potential drift is $425 \pm 60 \mu \mathrm{V} / \mathrm{h}(n=3)$ for all-solidstate $\mathrm{K}^{+}$-ISE with nanoporous gold as solid contact, which is lower than those of the carbon nanotube-based solid-contact $\mathrm{Ca}^{2+}$-ISEs $(493 \mu \mathrm{V} / \mathrm{h})$ and octanethiol modified gold nanoparticle-based solid-contact $\mathrm{K}^{+}$-ISEs $(660 \mu \mathrm{V} / \mathrm{h}) .{ }^{14,30}$

Effects of $\mathrm{O}_{2}, \mathrm{CO}_{2}$, and Light on the Potential Stability. The presence of $\mathrm{O}_{2}$ and $\mathrm{CO}_{2}$ in the sample solution may cause some undesirable effects for coated-wire ISEs, since they can permeate through the ISM to reach the surface of the electronic conductor. For example, $\mathrm{O}_{2}$ would affect the phase boundary potential by forming an oxygen half-cell at the surface of electronic conductor, while $\mathrm{CO}_{2}$ would change the $\mathrm{pH}$ of the water layer between the ISM and the electronic conductor and subsequently cause the potential drift. ${ }^{10,31}$ Therefore, the effects of $\mathrm{O}_{2}$ and $\mathrm{CO}_{2}$ on the potential stability of the $\mathrm{Au} / \mathrm{NPG} / \mathrm{K}^{+}$ISM electrode were investigated by purging the gases in a stirred $10^{-3} \mathrm{M} \mathrm{KCl}$ for about $30 \mathrm{~min}$. As shown in Figure 7, the slight potential disturbances are observed upon the introduction of both $\mathrm{O}_{2}$ and $\mathrm{CO}_{2}$, while after continuously purging the gases for about $5 \mathrm{~min}$, the potential responses remain almost constant. Additionally, the effect of light on the $\mathrm{Au} / \mathrm{NPG} / \mathrm{K}^{+}$ISM electrode was investigated by recording the potential response in a stirred $10^{-3} \mathrm{M} \mathrm{KCl}$ while turning on/off the

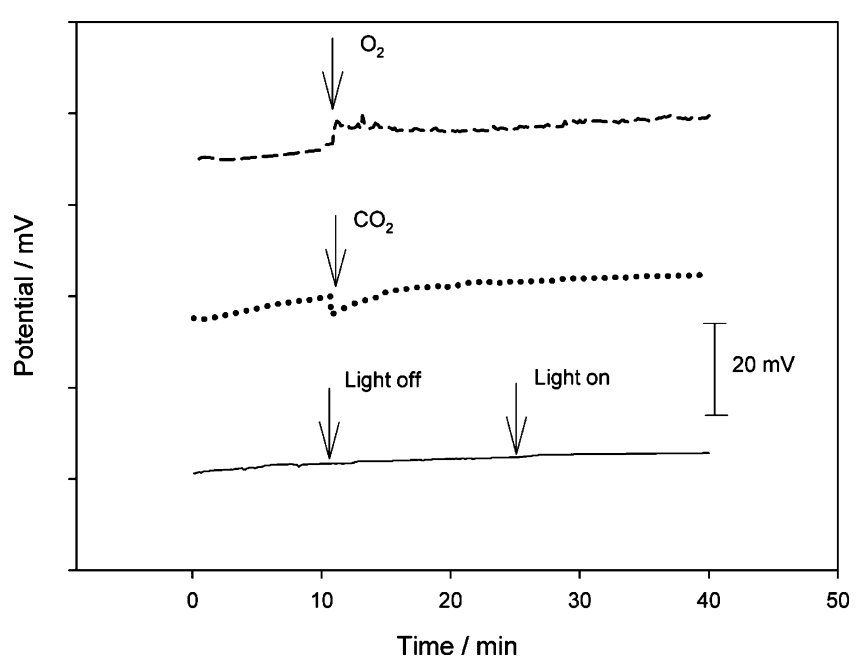

Figure 7. Effects of $\mathrm{O}_{2}$ (dashed line), $\mathrm{CO}_{2}$ (dotted line), and light (solid line) on the potential stability of $\mathrm{Au} / \mathrm{NPG} / \mathrm{K}^{+}-\mathrm{ISM}$ electrodes in $10^{-3} \mathrm{M} \mathrm{KCl}$. The saturation concentrations of both $\mathrm{O}_{2}$ and $\mathrm{CO}_{2}$ in aqueous solution at room temperature were used. 
ambient light. The potential response was found to be almost constant during the measurement (Figure 7), indicating that the NPG film-based solid contact has no light sensitivity.

Water Layer Test. The presence of the water layer between the ion-selective membrane and the electronic conductor may cause the long-term potential instability, ${ }^{6}$ which is due to the composition change caused by the re-equilibration of ions or some gases across the sensing membrane, e.g., $\mathrm{O}_{2}$ and $\mathrm{CO}_{2}$. Therefore, the potentiometric water layer test was performed to investigate the long-term potential stability of the NPG filmbased all-solid-state ISEs. After being conditioned in $10^{-3} \mathrm{M}$ $\mathrm{KCl}$ overnight, the $\mathrm{Au} / \mathrm{K}^{+}$-ISM and $\mathrm{Au} / \mathrm{NPG} / \mathrm{K}^{+}$-ISM electrodes were alternately measured in $0.1 \mathrm{M} \mathrm{KCl}$ for $1 \mathrm{~h}, 0.1 \mathrm{M}$ $\mathrm{NaCl}$ for $3 \mathrm{~h}$, and again $0.1 \mathrm{M} \mathrm{KCl}$ for $6 \mathrm{~h}$. As shown in Figure 8 , there is a clearly different potentiometric performance

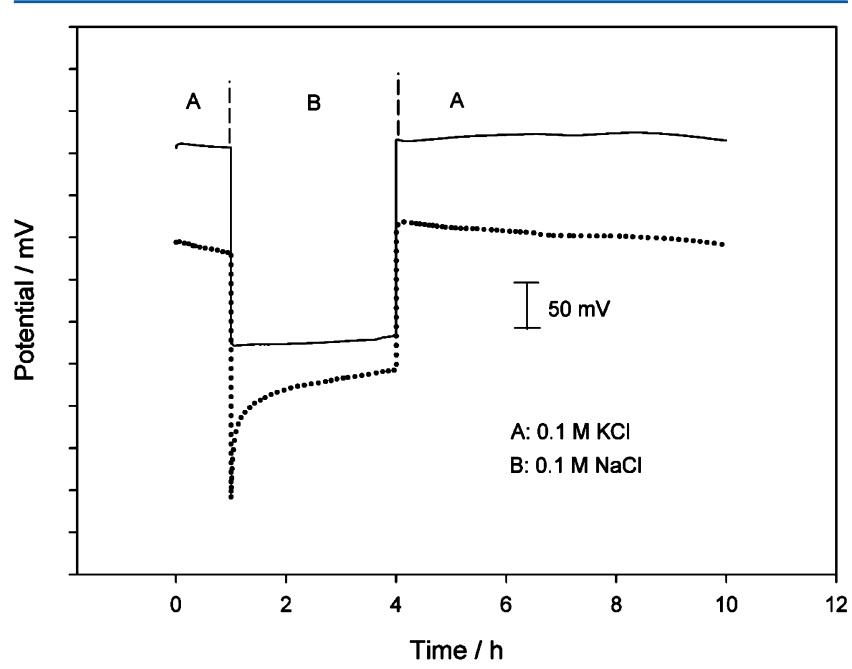

Figure 8. Water layer test for the $\mathrm{Au} / \mathrm{K}^{+}$-ISM (dotted line) and $\mathrm{Au} /$ $\mathrm{NPG} / \mathrm{K}^{+}$-ISM (solid line) electrodes.

between the $\mathrm{Au} / \mathrm{K}^{+}$-ISM and $\mathrm{Au} / \mathrm{NPG} / \mathrm{K}^{+}$-ISM electrodes. A positive potential drift is not clearly observed when changing the $\mathrm{Au} / \mathrm{NPG} / \mathrm{K}^{+}$-ISM electrode from primary ions $\left(\mathrm{K}^{+}\right)$to interfering ions $\left(\mathrm{Na}^{+}\right)$. Similarly, a negative potential drift is not observed within $6 \mathrm{~h}$ when changing the proposed electrodes from interfering ions to primary ions. The results compare favorably with those obtained for the $\mathrm{Au} / \mathrm{K}^{+}$-ISM electrode, which indicates a reduced water layer is formed between the nanoporous gold film and the ion-selective membrane.

Reusability of the NPG Film. To demonstrate the reusability of NPG film, the $\mathrm{Au} / \mathrm{NPG} / \mathrm{K}^{+}$-ISM electrode was placed in a stirred THF solvent to remove the ion-selective membrane and then thoroughly rinsed with ethanol and deionized water in sequence. The recycled $\mathrm{Au} / \mathrm{NPG}$ electrode was again evaluated by $\mathrm{CV}$ in $0.5 \mathrm{M} \mathrm{H}_{2} \mathrm{SO}_{4}$ to characterize the real surface area and in $0.1 \mathrm{M} \mathrm{KCl}$ to investigate the electrical double layer capacitance of the NPG film (Figure S6, Supporting Information). The surface area and the double layer capacitance of the NPG film are both found to not significantly change. The $\mathrm{K}^{+}$-ISM was then coated on the recycled NPG film surface. After the electrode was conditioned in $10^{-3} \mathrm{M} \mathrm{KCl}$, the potential response of the all-solid-state $\mathrm{K}^{+}$ISE was again investigated (Figure S7, Supporting Information). The potential performance of the recycled NPG filmbased all-solid-state $\mathrm{K}^{+}$-ISE is found to be consistent with that of the freshly prepared NPG film-based $\mathrm{K}^{+}$-ISE, which indicates that the NPG film is reusable for fabricating all-solid-state polymeric membrane ISEs.

\section{CONCLUSIONS}

This paper demonstrates that the in situ formed seamless NPG film can be used to develop stable and reliable all-solid-state ion-selective miniaturized electrodes, due to its large surface area, good conductivity, and high double layer capacitance in comparison with the bare gold wire electrode. The transducing principle is based on the bicontinuous electron- and ionconducting property of the ionophore-doped polymeric membrane/NPG film interlayer. The NPG film-based allsolid-state $\mathrm{K}^{+}$-ISE shows a stable potential response with a slope of $54.2 \mathrm{mV} / \mathrm{dec}$ in the linear range from $10^{-6}$ to $10^{-2} \mathrm{M}$ and a detection limit of $4.0 \times 10^{-7} \mathrm{M}$. Compared with the coated-wire ISE, the NPG film-based $\mathrm{K}^{+}$-ISE has been found to exhibit an improved potential stability with a reduced water layer. The seamless NPG film is reusable after removal of the ion-selective membrane with organic solvents, which offers a convenient way to save the costs for developing the all-solidstate ISEs. Unlike the additional intermediate layers as solid contacts, this work provides an in situ fabrication method for preparing solid contacts. The proposed NPG film-based allsolid-state ISEs are promising for miniaturization and mass fabrication.

\section{ASSOCIATED CONTENT}

\section{Supporting Information}

Additional information as noted in the text. This material is available free of charge via the Internet at http://pubs.acs.org.

\section{AUTHOR INFORMATION}

\section{Corresponding Author}

*E-mail: wqin@yic.ac.cn.

\section{Notes}

The authors declare no competing financial interest.

\section{ACKNOWLEDGMENTS}

This work was financially supported by the Instrument Developing Project of the Chinese Academy of Sciences (YZ201161), the National Natural Science Foundation of China $(21475148,41176081)$, and the Taishan Scholar Program of Shandong Province (TS20081159).

\section{REFERENCES}

(1) Bakker, E.; Pretsch, E. TrAC, Trends Anal. Chem. 2008, 27, 612618.

(2) Lindner, E.; Gyurcsányi, R. J. Solid State Electrochem. 2009, 13, $51-68$.

(3) Cattrall, R. W.; Freiser, H. Anal. Chem. 1971, 43, 1905-1906.

(4) Sutter, J.; Pretsch, E. Electroanalysis 2006, 18, 19-25.

(5) De Marco, R.; Veder, J.-P.; Clarke, G.; Nelson, A.; Prince, K.; Pretsch, E.; Bakker, E. Phys. Chem. Chem. Phys. 2008, 10, 73-76.

(6) Fibbioli, M.; Morf, W. E.; Badertscher, M.; de Rooij, N. F.; Pretsch, E. Electroanalysis 2000, 12, 1286-1292.

(7) Fibbioli, M.; Bandyopadhyay, K.; Liu, S.-G.; Echegoyen, L.; Enger, O.; Diederich, F.; Buhlmann, P.; Pretsch, E. Chem. Commun. 2000, 339-340.

(8) Bobacka, J.; Ivaska, A.; Lewenstam, A. Chem. Rev. 2008, 108, 329-351.

(9) Fouskaki, M.; Chaniotakis, N. Analyst 2008, 133, 1072-1075.

(10) Lai, C.-Z.; Fierke, M. A.; Stein, A.; Bühlmann, P. Anal. Chem. 2007, 79, 4621-4626. 
(11) Crespo, G. A.; Macho, S.; Rius, F. X. Anal. Chem. 2008, 80, 1316-1322.

(12) Li, F.; Ye, J.; Zhou, M.; Gan, S.; Zhang, Q.; Han, D.; Niu, L. Analyst 2012, 137, 618-623.

(13) Ping, J.; Wang, Y.; Ying, Y.; Wu, J. Anal. Chem. 2012, 84, 34733479.

(14) Jaworska, E.; Wójcik, M.; Kisiel, A.; Mieczkowski, J.; Michalska, A. Talanta 2011, 85, 1986-1989.

(15) Zhou, M.; Gan, S. Y.; Cai, B.; Li, F. H.; Ma, W. G.; Han, D. X.; Niu, L. Anal. Chem. 2012, 84, 3480-3483.

(16) Hu, J.; Zou, X. U.; Stein, A.; Bühlmann, P. Anal. Chem. 2014, 86, $7111-7118$

(17) Fouskaki, M.; Chaniotakis, N. A. Anal. Chem. 2005, 77, 17801784.

(18) Lindfors, T. J. Solid State Electrochem. 2009, 13, 77-89.

(19) Sutter, J.; Lindner, E.; Gyurcsányi, R.; Pretsch, E. Anal. Bioanal. Chem. 2004, 380, 7-14.

(20) Rubinova, N.; Chumbimuni-Torres, K.; Bakker, E. Sens. Actuators, B 2007, 121, 135-141.

(21) Sutter, J.; Radu, A.; Peper, S.; Bakker, E.; Pretsch, E. Anal. Chim. Acta 2004, 523, 53-59.

(22) Lindfors, T.; Sundfors, F.; Höfler, L.; Gyurcsányi, R. E. Electroanalysis 2011, 23, 2156-2163.

(23) Jia, F. L.; Yu, C. F.; Ai, Z. H.; Zhang, L. Z. Chem. Mater. 2007, 19, 3648-3653.

(24) Trasatti, S.; Petrii, O. A. Pure Appl. Chem. 1991, 63, 711-734.

(25) Crespo, G. A.; Macho, S.; Bobacka, J.; Rius, F. X. Anal. Chem. 2008, 81, 676-681.

(26) Hernández, R.; Riu, J.; Bobacka, J.; Vallés, C.; Jiménez, P.; Benito, A. M.; Maser, W. K.; Rius, F. X. J. Phys. Chem. C 2012, 116, 22570-22578.

(27) Bobacka, J. Anal. Chem. 1999, 71, 4932-4937.

(28) Bobacka, J.; Lewenstam, A.; Ivaska, A. J. Electroanal. Chem. 2000, 489, 17-27.

(29) Bakker, E. J. Electrochem. Soc. 1996, 143, L83-L85.

(30) Hernandez, R.; Riu, J.; Rius, F. X. Analyst 2010, 135, 19791985.

(31) Cattrall, R. W.; Drew, D. M.; Hamilton, I. C. Anal. Chim. Acta 1975, 76, 269-277. 